New mitogenome and nuclear evidence on the phylogeny and taxonomy of the highly zoonotic tapeworm Echinococcus granulosus sensu stricto

Kinkar, Liina

2017-08

Kinkar , L , Laurimae , T , Sharbatkhori , M , Mirhendi , H , Kia , E B , Ponce-Gordo , F , Andresiuk, V , Simsek , S , Lavikainen, A , Irshadullah, M , Umhang , G , Oudni-M'rad , M , Acosta-Jamett , G, Rehbein , S \& Saarma , U 2017, ' New mitogenome and nuclear evidence on the phylogeny and taxonomy of the highly zoonotic tapeworm Echinococcus granulosus sensu stricto ' , Infection, genetics and evolution , vol. 52 , pp. 52-58 . https://doi.org/10.1016/j.meegid.20

http://hdl.handle.net/10138/237086

https://doi.org/10.1016/j.meegid.2017.04.023

publishedVersion

Downloaded from Helda, University of Helsinki institutional repository.

This is an electronic reprint of the original article.

This reprint may differ from the original in pagination and typographic detail.

Please cite the original version. 
Research paper

\title{
New mitogenome and nuclear evidence on the phylogeny and taxonomy of the highly zoonotic tapeworm Echinococcus granulosus sensu stricto
}

\author{
Liina Kinkar a, Teivi Laurimäe a , Mitra Sharbatkhori ${ }^{\text {b }}$, Hossein Mirhendi ${ }^{c}$, Eshrat Beigom Kia ${ }^{\text {d }}$, \\ Francisco Ponce-Gordo ${ }^{\mathrm{e}}$, Vanessa Andresiuk ${ }^{\mathrm{f}}$, Sami Simsek ${ }^{\mathrm{g}}$, Antti Lavikainen ${ }^{\mathrm{h}}$, Malik Irshadullah ${ }^{\mathrm{i}}$, \\ Gérald Umhang ${ }^{\mathrm{j}}$, Myriam Oudni-M'rad ${ }^{\mathrm{k}}$, Gerardo Acosta-Jamett ${ }^{1}$, Steffen Rehbein ${ }^{\mathrm{m}}$, Urmas Saarma ${ }^{\mathrm{a}, *}$ \\ ${ }^{a}$ Department of Zoology, Institute of Ecology and Earth Sciences, University of Tartu, Vanemuise 46, 50410 Tartu, Estonia \\ ${ }^{\mathrm{b}}$ Laboratory Sciences Research Center, Golestan University of Medical Sciences, Gorgan, Iran \\ c Department of Medical Mycology and Parasitology, School of Medicine, Isfahan University of Medical Sciences, Isfahan, Iran \\ d Department of Medical Parasitology and Mycology, School of Public Health, Tehran University of Medical Sciences, Tehran, Iran \\ e Departmento de Parasitología, Facultad de Farmacia, Plaza Ramón y Cajal s/n, UCM, Madrid, Spain \\ ${ }^{\mathrm{f}}$ Laboratorio de Zoonosis Parasitarias, FCEyN, UNMdP, Funes 3350, CP: 7600, Mar del Plata, Buenos Aires, Argentina \\ ${ }^{\mathrm{g}}$ Department of Parasitology, Faculty of Veterinary Medicine, University of Firat, 23119 Elazig, Turkey

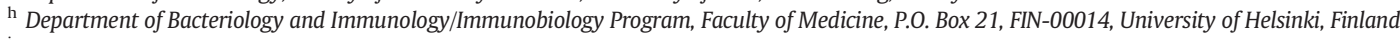 \\ ${ }^{i}$ Section of Parasitology, Department of Zoology, Aligarh Muslim University, Aligarh 202002, India \\ ${ }^{\mathrm{j}}$ Anses, Wildlife Surveillance and Eco-epidemiology Unit, National Reference Laboratory for Echinococcus spp., Nancy Laboratory for Rabies and Wildlife, 54220 Malzéville, France \\ k LP3M: Laboratory of Medical and Molecular Parasitology-Mycology, LR12ES08, Faculty of Pharmacy, University of Monastir, 5000 Monastir, Tunisia \\ ${ }^{1}$ Instituto de Medicina Preventiva Veterinaria y Programa de Investgación Aplicada en Fauna Silvestre, Facultad de Ciencias Veterinarias, Universidad Austral de Chile, Casilla 567, Valdivia, Chile \\ ${ }^{\mathrm{m}}$ Merial GmbH, Kathrinenhof Research Center, Walchenseestr. 8-12, 83101 Rohrdorf, Germany
}

\section{A R T I C L E I N F O}

\section{Article history:}

Received 28 November 2016

Received in revised form 20 March 2017

Accepted 26 April 2017

Available online 27 April 2017

\section{Keywords:}

Cystic echinococcosis

Echinococcus granulosus sensu stricto

Echinococcus taxonomy

Hydatidosis

Mitochondrial genome

Nuclear genes

\begin{abstract}
A B S T R A C T
Cystic echinococcosis, a zoonotic disease caused by Echinococcus granulosus sensu lato (s. 1.), is a significant global public health concern. Echinococcus granulosus s. l. is currently divided into numerous genotypes (G1-G8 and G10) of which G1-G3 are the most frequently implicated genotypes in human infections. Although it has been suggested that G1-G3 could be regarded as a distinct species E. granulosus sensu stricto (s. s.), the evidence to support this is inconclusive. Most importantly, data from nuclear DNA that provide means to investigate the exchange of genetic material between G1-G3 is lacking as none of the published nuclear DNA studies have explicitly included G2 or G3. Moreover, the commonly used relatively short mtDNA sequences, including the complete cox1 gene, have not allowed unequivocal differentiation of genotypes G1-G3. Therefore, significantly longer mtDNA sequences are required to distinguish these genotypes with confidence. The main aim of this study was to evaluate the phylogenetic relations and taxonomy of genotypes G1-G3 using sequences of nearly complete mitogenomes (11,443 bp) and three nuclear loci (2984 bp). A total of 23 G1-G3 samples were analysed, originating from 5 intermediate host species in 10 countries. The mtDNA data demonstrate that genotypes G1 and G3 are distinct mitochondrial genotypes (separated by 37 mutations), whereas G2 is not a separate genotype or even a monophyletic cluster, but belongs to G3. Nuclear data revealed no genetic separation of G1 and G3, suggesting that these genotypes form a single species due to ongoing gene flow. We conclude that: (a) in the taxonomic sense, genotypes G1 and G3 can be treated as a single species E. granulosus s. s.; (b) genotypes G1 and G3 should be regarded as distinct genotypes only in the context of mitochondrial data; (c) we recommend excluding G2 from the genotype list.
\end{abstract}

(c) 2017 Elsevier B.V. All rights reserved.

\section{Introduction}

Cystic echinococcosis (CE), a zoonotic disease caused by the larval stage of tapeworm Echinococcus granulosus sensu lato (s. 1.), is a

\footnotetext{
* Corresponding author at: Department of Zoology, Institute of Ecology and Earth Sciences, University of Tartu, Tartu 51014, Estonia.

E-mail address: Urmas.Saarma@ut.ee (U. Saarma).
}

significant global public health concern (Eckert et al. 2001; Alvarez Rojas et al. 2014; Marcinkute et al. 2015). The life cycle of the parasite involves mainly dogs and wild carnivores as definitive hosts and a wide range of domestic and wild mammals as intermediate hosts, but also humans as aberrant intermediate host (e.g. Eckert et al. 2001; Moks et al. 2006, 2008; Deplazes et al. 2011; Laurimaa et al. 2015a). CE is listed among the most severe parasitic diseases in humans, ranking second in the list of food-borne parasites globally (FAO/WHO report, 
2014) and representing one of the 17 Neglected Tropical Diseases prioritised by the World Health Organization (Daumerie et al. 2010).

Echinococcus granulosus s. l. exhibits considerable variability in terms of genetic diversity, morphology, host range, infectivity to humans, pathogenicity, antigenicity, developing rate and other aspects (e.g. Eckert et al. 2001; Thompson, 2008; Gholami et al. 2011; Romig et al. 2015). Molecular studies have identified a number of genotypes/species within the E. granulosus complex (Bowles et al. 1992; Bowles et al. 1994; Thompson and McManus, 2002; Lavikainen et al. 2003; Nakao et al. 2007; Hüttner et al. 2008; Thompson, 2008; Saarma et al. 2009; Knapp et al. 2011) that are closely related to other species in the genus Echinococcus (Knapp et al. 2015). Traditionally, the complex is considered to consist of genotypes G1-G8, G10 and E. felidis (Bowles et al. 1992; Bowles et al. 1994; Lavikainen et al. 2003; Hüttner et al. 2008). A novel genotype recently discovered from Ethiopia by Wassermann et al. (2016) adds even more complexity. Suggestions have been made to split the genotypes into distinct species: $E$. granulosus sensu stricto (s. s.; genotypes G1-G3), E. equinus (G4), E. ortleppi (G5) and E. canadensis (G6-G8 and G10), or E. intermedius (G6, G7) and E. canadensis (G8, G10) (Thompson and McManus, 2002; Nakao et al. 2007; Thompson, 2008; Saarma et al. 2009; Knapp et al. 2011; Thompson, 2016). However, the evidence is still inconclusive, especially for genotype groups G1-G3 and G6-G10 (e.g. Saarma et al. 2009; Nakao et al. 2015; Romig et al. 2015; Lymbery, 2016).

Echinococcus granulosus s. s. (genotypes G1-G3) is spread globally among wild and domestic animals, with highly endemic foci in South America, the Mediterranean basin and Central Asia (Dakkak et al. 2010; Hajialilo et al. 2012; Rostami et al. 2015; Boufana et al. 2015; Zhang et al. 2015; Cusher et al. 2016; Laurimäe et al. 2016). E. granulosus S. s. is also the most frequently implicated Echinococcus species in human infections, $88 \%$ worldwide, according to a recent estimate by Alvarez Rojas et al. (2014), therefore deserving particularly close attention. Dogs may present a considerable risk factor in the spread of CE due to their close contact with humans. Although generally the infection rates for humans are higher in rural areas (Possenti et al. 2016), there is increasing potential for exposure in urban environment. Indeed, using non-invasive molecular diagnostics (Laurimaa et al. 2015b), genotype G1 has been recently found in urban dogs (Laurimaa et al. 2015a).

The original molecular definitions of genotypes G1-G3 were based on 366 bp of the cox1 gene (Bowles et al. 1992). It became immediately apparent that genotypes G1-G3 are genetically more closely related to each other than to any other known genotype and a proposal was made to treat G1-G3 as a single species (Thompson et al. 1995). To evaluate the taxonomy of G1-G3, phylogenetic analysis of nuclear loci is absolutely crucial, as it would provide means to investigate the exchange of genetic material between G1-G3. However, nuclear evidence on the inter- and intragenotypic variation of G1-G3 is still missing. Moreover, previous taxonomic studies based on multiple nuclear loci have never explicitly included G2 or G3 (Hüttner et al. 2008; Saarma et al. 2009; Knapp et al. 2011). Thus, despite the assumptions that mitochondrial genotypes G1-G3 can be regarded as a distinct species E. granulosus s. s., the evidence is still inconclusive.

An important prerequisite prior to the taxonomic evaluation of $E$. granulosus s. s. is the correct allocation of samples into genotypes. To date, the commonly used relatively short mtDNA sequences in analysis have not been able to clearly differentiate genotypes G1-G3 due to low phylogenetic resolution (Busi et al. 2007; Vural et al. 2008; Casulli et al. 2012; Yanagida et al. 2012; Andresiuk et al. 2013; Romig et al. 2015). As a result, allocation to genotypes G1-G3 has been dubious and without a clear definition. This problem is also highlighted in a recently published network of 137 haplotypes in Romig et al. (2015). Using the 1609 bp sequence of the cox1 gene, the G1-G3 phylogenetic network revealed a low level of differentiation into G1 and G2/G3, but without clear differentiation into separate haplogroups. Furthermore, a large proportion of the haplotypes described in Romig et al. (2015) were not homologous with any of the sequences of G1, G2 or G3 originally described in
Bowles et al. (1992). However, using significantly longer mtDNA sequences (Kinkar et al. 2016; Laurimäe et al. 2016) could provide means to differentiate G1-G3 from each other with confidence. The correct genotyping of this highly zoonotic cluster would also be of great epidemiological importance as it forms the basis for further analysis regarding the possible differences between these genotypes (e.g. infectivity to humans).

Delimiting species is generally a stepwise process (see also Lymbery, 2016). First step is to reconstruct a phylogeny (a phylogenetic tree or network) to identify monophyletic groupings, i.e. organisms that share a common ancestor and where taxa are more closely related to each other than to any other groupings. Second step is to analyse gene flow between these monophyletic groupings in order to identify: (i) groupings for which cohesion is maintained by gene flow, (ii) for which there is no gene flow. If, for example, G1 and G3 represent different mtDNA lineages, whereas on the basis of nDNA data there is no separation of G1 and G3 due to genetic exchange, then one can consider G1 and G3 as a single species. From the taxonomic point of view, the analysis should ideally involve genotypes from various geographic locations, including sympatric and geographically distant ones. The results based on genetic data should also be evaluated in the context of other scientific evidence (e.g. morphological and ecological data, host range, infectivity to humans, developing rate), if such data is available.

The aim of this study was to analyse the phylogenetic relations and taxonomic status of E. granulosus s. s. genotypes G1-G3 using $11,443 \mathrm{bp}$ of mtDNA ( $~ 85 \%$ of the whole mitogenome) and $2984 \mathrm{bp}$ of three nuclear genes (cal, tgf, ef1) analysing samples from different host species covering a wide geographical range, but also from areas where E. granulosus s. s. genotypes occur in sympatry.

\section{Materials and methods}

\subsection{Parasite material}

A total of 23 E. granulosus s. s. samples were analysed in this study, originating from 5 intermediate host species (sheep, cattle, buffalo, camel and human) in 10 countries: India $(n=2)$, $\operatorname{Iran}(n=4)$, Turkey $(n=4)$, Spain $(n=5)$, France $(n=3)$, Finland (patient from Algeria; $\mathrm{n}=1)$, Chile $(\mathrm{n}=1)$, Argentina $(\mathrm{n}=1)$, Albania $(\mathrm{n}=1)$ and Tunisia $(\mathrm{n}=1$; Fig. 1 ; Table 1 ). In addition, one E. equinus (G4) sample from a Turkish donkey and three E. ortleppi (G5) samples from Indian buffaloes were analysed to evaluate their genetic distance from genotypes G1G3. Samples were obtained during routine meat inspections or from hospital cases and were ethanol-preserved at $-20{ }^{\circ} \mathrm{C}$ until further use.

\subsection{DNA extraction}

DNA was extracted from protoscoleces or cyst membranes using High Pure PCR Template Preparation Kit (Roche Diagnostics, Mannheim, Germany), following the manufacturer's protocols.

\section{3. $P C R$ amplification and sequencing of $m t D N A$}

For mtDNA sequencing we used 17 primers described in Kinkar et al. (2016) and Laurimäe et al. (2016), whereas 7 primers were newly designed (Table 2). Sequencing was performed using the same primers as for the initial PCR amplification. Cycle parameters for PCR and sequencing were as described in Kinkar et al. (2016). All mtDNA sequences were deposited in GenBank and are available under accession numbers KY766882-KY766908 (Table 1).

\subsection{PCR amplification and sequencing of nuclear DNA}

Amplification and sequencing of 3 nuclear genes (2984 bp in total): transforming growth factor beta receptor kinase (tgf; 937 bp), calreticulin (cal; $1272 \mathrm{bp}$ ) and elongation factor 1 alpha ( $e f 1 ; 775 \mathrm{bp}$ ) 


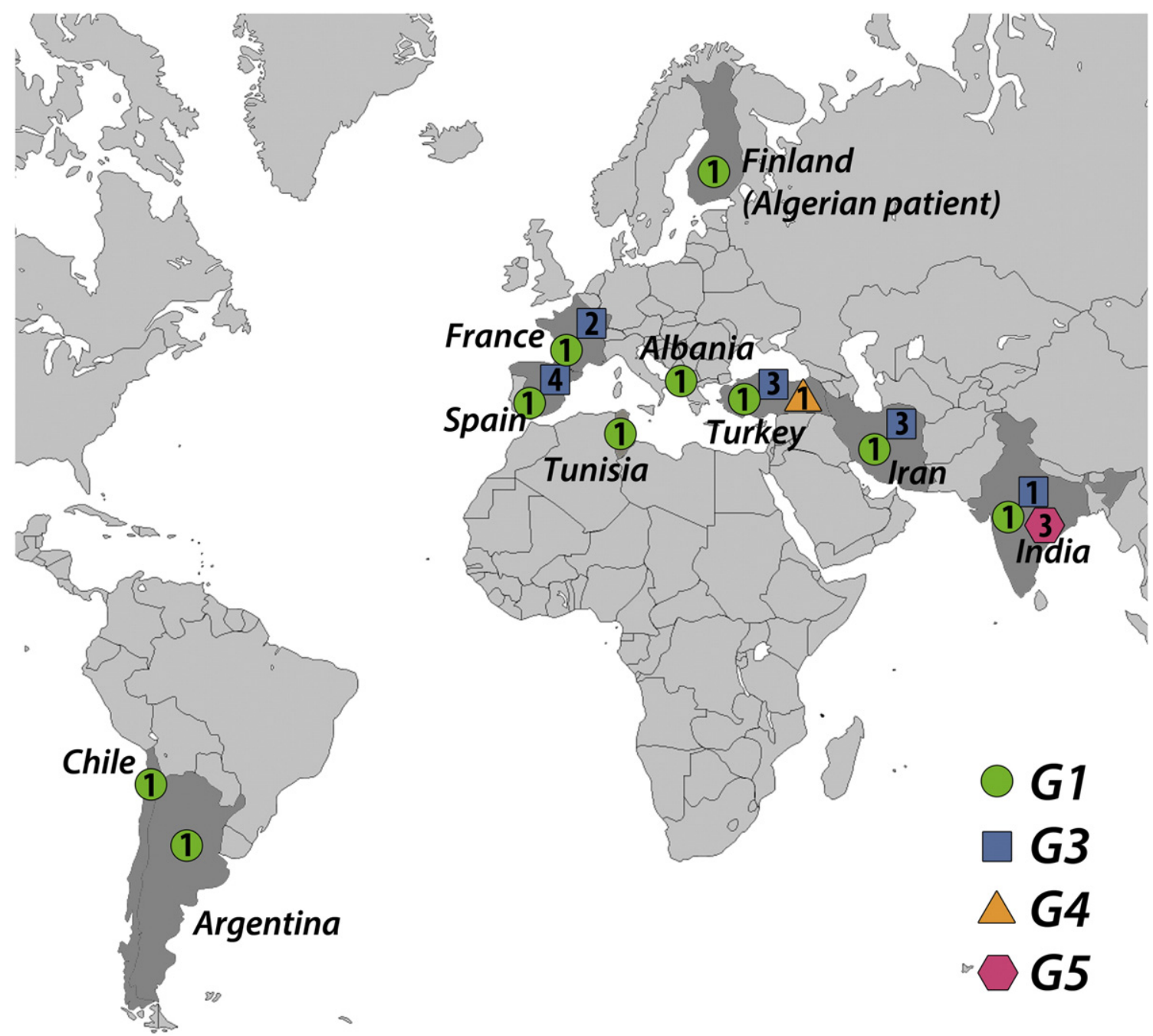

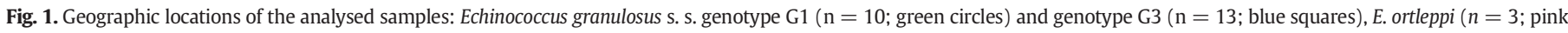
hexagon) and $E$. equinus ( $\mathrm{n}=1$; yellow triangle).

Table 1

Data on the E. granulosus s. s. samples analysed in this study.

\begin{tabular}{|c|c|c|c|c|}
\hline $\begin{array}{l}\text { mtDNA } \\
\text { haplotype }\end{array}$ & $\begin{array}{l}\text { Mitochondrial genotype } \\
\text { confirmed in this study }\end{array}$ & Location & Host & $\begin{array}{l}\text { mtDNA } \\
\text { accession } \mathrm{nr} \text { in } \\
\text { GenBank }\end{array}$ \\
\hline SPA5 & G1 & Spain & Sheep & KY766886 \\
\hline FIN1 & G1 & Finland & Human & KY766884 \\
\hline TUN1 & G1 & Tunesia & Sheep & KY766885 \\
\hline ARG1 & G1 & Argentina & Cattle & KY766882 \\
\hline IND2 & G1 & India & Buffalo & KY766891 \\
\hline CHI1 & G1 & Chile & Cattle & KY766890 \\
\hline TUR4 & G1 & Turkey & Sheep & KY766888 \\
\hline FRA3 & G1 & France & Cattle & KY766889 \\
\hline ALB1 & G1 & Albania & Sheep & KY766883 \\
\hline IRA4 & G1 & Iran & Sheep & KY766887 \\
\hline TUR1 & G3 & Turkey & Sheep & KY766901 \\
\hline SPA1 & G3 & Spain & Sheep & KY766900 \\
\hline SPA2 & G3 & Spain & Sheep & KY766896 \\
\hline FRA1 & G3 & France & Sheep & KY766893 \\
\hline SPA4 & G3 & Spain & Sheep & KY766897 \\
\hline IND1 & G3 & India & Buffalo & KY766902 \\
\hline IRA3 & G3 & Iran & Camel & KY766899 \\
\hline IRA1 & G3 & Iran & Camel & KY766894 \\
\hline IRA2 & G3 & Iran & Camel & KY766895 \\
\hline FRA2 & G3 & France & Sheep & KY766892 \\
\hline SPA3 & G3 & Spain & Sheep & KY766903 \\
\hline TUR2 & G3 & Turkey & Cattle & KY766904 \\
\hline TUR3 & G3 & Turkey & Sheep & KY766898 \\
\hline
\end{tabular}

was carried out according to Saarma et al. (2009). All nuclear sequences were deposited in GenBank and are available under accession numbers KY766909-KY766920.

\subsection{Data analysis}

Sequences were assembled in CodonCode v6.0.2, manually corrected in BioEdit v7.2.5 and aligned with corresponding sequences available in GenBank (G1: AF297617; G3: KJ559023; G4: AB786665; G5: AB235846; cal: EU834931; ef1: EU834898; tgf: EU834910) (Le et al. 2002; Nakao et al. 2007; Nakao et al. 2013; Saarma et al. 2009; Wang et al. 2016). Phylogenetic networks were calculated using Network v4.612 (Bandelt et al. 1999) (http://www.fluxusengineering. com, Fluxus Technology Ltd., 2004). Networks were constructed separately for mitochondrial and nuclear markers.

\section{Results}

In the mtDNA analysis, a total of 23 E. granulosus s. S., one E. equinus and three $E$. ortleppi samples were successfully analysed, yielding final mtDNA alignment of $11,502 \mathrm{bp}$ (the sequence length was 11,442 $11,443 \mathrm{bp}$ for the E. granulosus s. s. samples, $11,465 \mathrm{bp}$ for the E. equinus sample, and 11,466 bp for the E. ortleppi samples).

Nuclear markers cal, ef 1 and tgf were successfully PCR-amplified for the same set of samples, except for a putative G2 genotype from Spain 
Table 2

Primers used for analysis; positions are according to AF297617 in GenBank (Le et al. 2002).

\begin{tabular}{|c|c|c|c|c|}
\hline Primer & Primer sequence & Primer position & PCR product length & Reference \\
\hline Ef1 & TCGTTTTACACGCGATTGAACT & $4924 \ldots 4945$ & & {$[1]^{\mathrm{a}},[2]^{\mathrm{a}}$} \\
\hline Er1 & ACCTGCTATGCAGCCCTATT & $6147 \ldots 6166$ & $1243 \mathrm{bp}$ & {$[1],[2]$} \\
\hline E2fn & GATGCTGTTAACTTCAAGAAATG & $6034 \ldots 6056$ & & {$[1],[2]$} \\
\hline E2r2 & CTCAAAGCATTCAAACGC & $7053 \ldots 7070$ & $1037 \mathrm{bp}$ & {$[1],[2]$} \\
\hline E3fn & GTTGATTCGTGTTAATTTTTTGGAG & $6873 \ldots 6897$ & & {$[1],[2]$} \\
\hline E3rn & GAAAACATAGCAAACAACAACCC & $7573 \ldots 7595$ & 723 bp & {$[1],[2]$} \\
\hline $\mathrm{E} 4 \mathrm{f} 2$ & GTGATCCTATTTTATTTCAAC & $7436 \ldots 7456$ & & {$[1],[2]$} \\
\hline E4rn & GCTACCTTTGCACAGTCAATATAC & $8939 \ldots 8962$ & $1527 \mathrm{bp}$ & This study \\
\hline E5fn & GGTACCTAGTTTTTGTTATATTGT & $8712 \ldots 8735$ & & This study \\
\hline E5rn & GAATCGCTCACTGCCAAACCA & $9813 \ldots 9833$ & 1122 bp & This study \\
\hline E6f & TAAGGGTGATGCAATTTGAG & $9588 \ldots 9607$ & & {$[1],[2]$} \\
\hline E6r & ACAACCATCTACAGCACGAA & $10,812 \ldots .10,831$ & $1244 \mathrm{bp}$ & [1], [2] \\
\hline E7fn & GATGCTGTTCCTGGTCGTCTTAATC & $10,623 \ldots .10,647$ & & This study \\
\hline E7rn & CAATCAACTTCAACAACATAAACC & $11,992 \ldots .12,015$ & $1393 \mathrm{bp}$ & This study \\
\hline E8fn & GCTTATGTTACGGCCATAAGA & $11,716 \ldots 11,736$ & & This study \\
\hline E8rn & TGCTTAGTAAAAAACACCCCA & $12,764 \ldots 12,784$ & $1069 \mathrm{bp}$ & This study \\
\hline E10f & GATTACTGTTACTGGTTTTCA & $312 \ldots 332$ & & {$[1],[2]$} \\
\hline E10r & CAACTTAAAAACAAGCATCATCA & $1756 \ldots 1778$ & $1467 \mathrm{bp}$ & {$[1],[2]$} \\
\hline E11f & TTTTATGCTATTCTTCGGTGTA & $1521 \ldots 1542$ & & {$[1],[2]$} \\
\hline E11r & САAАAАСАССТСАТТАAАССАС & $3278 \ldots 3299$ & 1779 bp & [1], [2] \\
\hline E12f & TTGTGGTGTTTTTATGATG & $2922 \ldots 2940$ & & {$[1],[2]$} \\
\hline E12r & CACAGACGATAACCCAGA & $4204 \ldots 4221$ & $1300 \mathrm{bp}$ & {$[1],[2]$} \\
\hline E13f & CGGGTCTTTTATTTTGATGTTG & $4003 \ldots 4024$ & & [1], [2] \\
\hline $\mathrm{E} 13 \mathrm{r}$ & GATCCAAAAGCACATCGA & $5507 \ldots 5524$ & $1522 \mathrm{bp}$ & {$[1],[2]$} \\
\hline
\end{tabular}

[1] Kinkar et al. (2016).

[2] Laurimäe et al. (2016).

a Note that these publications report identical primers due to simultaneous publication.

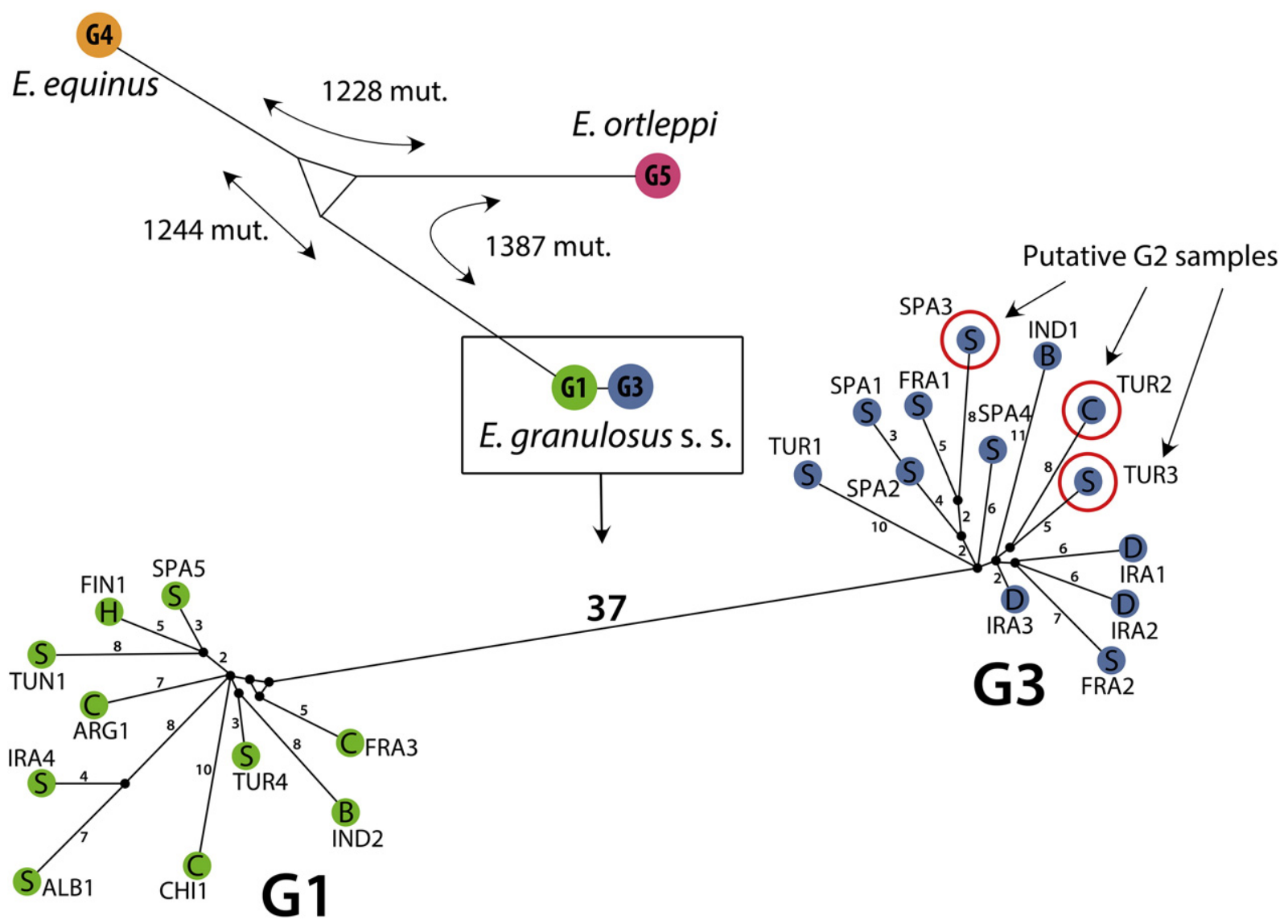

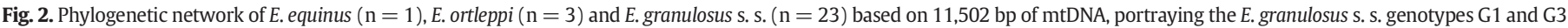

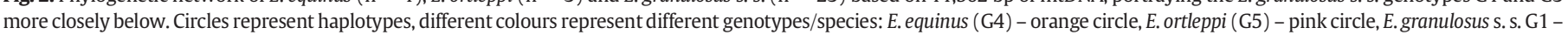

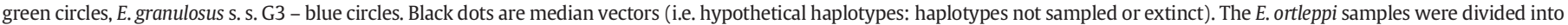

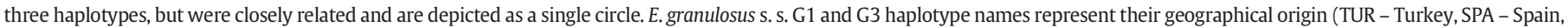

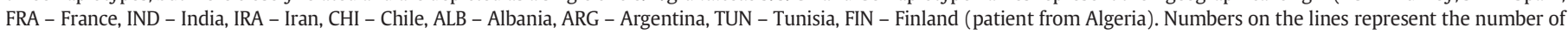
mutations. Letters inside the E. granulosus s. s. haplotypes represent host species: S - sheep, C - cattle, B - buffalo, H - human, D - dromedary camel. 
(SPA3) that did not yield positive PCR results with the nuclear markers. The final length of the nuclear genes in alignment was $2984 \mathrm{bp}$.

\section{1. mtDNA networks}

Echinococcus equinus and E. ortleppi mtDNA haplotypes were separated from E. granulosus s. s. by 1244 and 1387 mutations, respectively. The genetic distance between E. equinus and E. ortleppi was 1228 mutations (Fig. 2).

Echinococcus granulosus s. s. samples were divided into two haplogroups (Fig. 2). One haplogroup included 10 samples, which were highly homologous with the G1 mitogenome sequence AF297617 in GenBank (Le et al. 2002). Of these, six haplotypes (FIN1, TUN1, ARG1, TUR4, CHI1, IND2) contained the originally described G1 sequence sensu Bowles et al. (1992; 366 bp of cox1) (Table 1). The other haplogroup included 13 samples, which were highly homologous with the G3 mitogenome sequence KJ559023 in GenBank (Wang et al. 2016). Seven haplotypes (SPA1, SPA2, SPA4, IRA1, IRA2, IRA3, FRA2) in this haplogroup contained the originally described G3 sequences sensu 366 bp of cox1 in Bowles et al. (1992) (Table 1). Therefore these two haplogroups corresponded to the E. granulosus s. S. mitochondrial genotypes G1 and G3 and were named accordingly. The G1 and G3 haplogroups were separated by 37 mutations. Three samples (SPA3, TUR2, TUR3) that corresponded to genotype G2 according to the 366 bp of cox1 in Bowles et al. (1992), positioned inside the G3 cluster (Table 1; Fig. 2), but were not monophyletic. However, seven haplotypes (SPA5, FRA3, ALB1, IRA4, TUR1, FRA1, IND1) could not be genotyped according to the original molecular definition in Bowles et al. (1992) based on the $366 \mathrm{bp}$ fragment of the cox1 gene (Table 1).

\section{2. nDNA networks}

The analysed 26 sequences based on the 3 nuclear genes were divided into 4 distinct sequences (Fig. 3). Echinococcus granulosus s. s. samples $(\mathrm{n}=22$ ) comprised of 2 sequences, separated by a single mutation. One sequence was dominant, comprising 20 E. granulosus s. s. samples, whereas the other included only 2 samples (FRA3 and SPA5). The three analysed E. ortleppi samples had an identical nuclear sequence, separated from E. granulosus s. s. by 36 mutations. The $E$. equinus sample was separated from E. ortleppi and E. granulosus s. s. by 23 and 45 mutations, respectively.

\section{Discussion}

Sequencing a large portion of the mtDNA in analysis is highly recommended when the aim is to obtain high-resolution phylogeny (e.g. Keis et al. 2013; Kinkar et al. 2016; Laurimäe et al. 2016). The results in this study based on the nearly complete mitochondrial genome sequences clearly demonstrate that genotypes G1 and G3 form distinct mitochondrial haplogroups, separated from each other by 37 mutations (Fig. 2). However, not all of these are diagnostic and defining the precise set of diagnostic nucleotides requires a much larger sample size (ongoing project).

To date, samples have often been allocated to genotypes G1-G3 without a clear definition: many haplotypes cannot be unequivocally designated to any of the genotypes originally described in Bowles et al. (1992). Even the analysis of the full cox1 gene (1609 bp) has not allowed clear differentiation of genotypes G1-G3 (see Romig et al. 2015). In this study, the considerably longer mtDNA sequences (11,443 bp) have placed G1 and G3 into distinct haplogroups, corresponding to mitochondrial genotypes G1 and G3. Thus, sequencing a significant portion of the mitochondrial genome has allowed for the first time to differentiate genotypes G1 and G3 with confidence. It is important to note that the G1 and G3 samples in this study were obtained not only from a wide geographical range, but also from countries where they exist in sympatry: India, Iran, Turkey, Spain and France (Fig. 1). Also, several host species analysed in this study were common between genotypes G1 and G3 (sheep, cattle and buffalo, see Fig. 2). Thus, the separation of these groups cannot be explained by clustering according to geographical origin or host species. Due to the relatively small number of samples analysed in this study, only a portion of the mitochondrial variation of genotypes G1 and G3 is presented. Therefore, it is possible that future studies involving significantly more samples may reveal haplotypes that position between G1 and G3 in mtDNA-based phylogenetic networks. However, these cases are probably rare since our analysis that included G1 and G3 samples from both geographically overlapping and highly distant locations demonstrate that maternal lineages of G1 and G3 are highly divergent and cluster separately (Fig. 2).

The results derived from mitochondrial data do not necessarily mean that genotypes G1 and G3 are separate biological entities. MtDNA does not recombine and mutations to different mtDNA lineages accumulate at random. Once a new mitochondrial mutation becomes fixed in a population, it forms a new mitochondrial lineage that is separate from the ancestral one. From this point onwards, mutations continue to fix progressively in an independent manner in both the new and

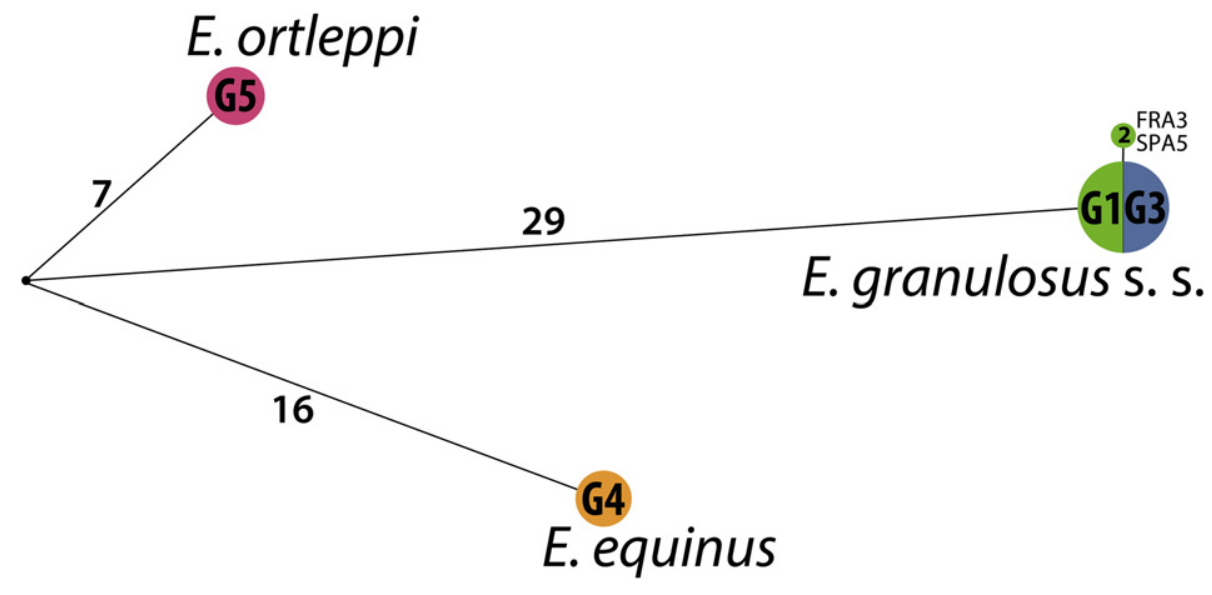

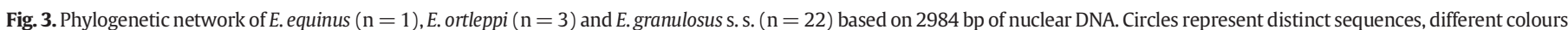

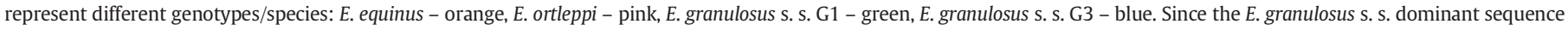

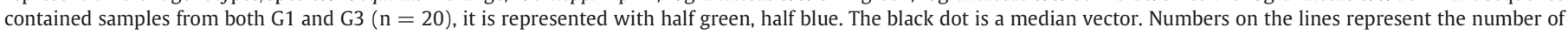
mutations. The number inside the sequence FRA3, SPA5 represents the number of samples. 
ancestral mitochondrial lineages. Although mutations also accumulate into the nuclear genome at random, nuclear genes undergo recombination and if there is no barrier for gene-flow, then nuclear genes do not show separation into genetically distinct populations (Saarma et al. 2009). Indeed, our data based on three nuclear genes enabled to distinguish E. granulosus S. S., E. equinus and E. ortleppi from each other with confidence, whereas there was no separation between genotypes G1 and G3 (Fig. 3). Therefore, our study confirms that in the taxonomic sense G1 and G3 can be regarded as a single species E. granulosus sensu stricto, which is further supported by a notion that G1 and G3 both have a wide geographical overlap and similar host spectra; hence there are limited ecological differences between these genotypes. Thus, this is the first study that confirms the species status of $E$. granulosus s. s. Also, as these results were unambiguous, we conclude that the sample size in this study was sufficient to confirm the species status of E. granulosus S. S. If the results had suggested that genotypes G1 and G3 are different species, contradicting earlier assumptions, then more samples would have been needed to confirm this finding.

Our data suggests that G2 is not a valid genotype even in the mitochondrial context. Three samples, matching the original molecular definition of genotype G2 sensu 366 bp of cox1 (Bowles et al. 1992), clustered together with G3 samples based on mtDNA and with both G1 and G3 genotypes based on nuclear genes (Table 1; Fig. 2; Fig. 3). Moreover, the putative G2 samples in this study were not monophyletic. We therefore suggest excluding G2 from the genotype list. Although the G2 genotype was originally described from a sheep in Tasmania (Bowles et al. 1992), a location which was not represented in this study, all analysed G2 samples were, sensu Bowles et al. (1992), genetically identical to the originally described Tasmanian sheep samples. Therefore, the G2 samples analysed in this study were adequate for investigating the validity of this genotype.

We conclude that in the taxonomic sense, genotypes G1 and G3 should be treated as single species E. granulosus s. s. It is also important to note that G1 and G3 can be regarded as distinct genotypes only in the context of mitochondrial data and that G2 is not a valid genotype even in the mitochondrial context. Although possible differences in the epidemiology between genotypes G1 and G3 are largely unknown and remain to be studied in the future, applying up-to-date molecular diagnostics to separate genotypes G1 and G3 correctly is an important prerequisite to perform such studies.

\section{Conflict of interest}

Authors declare no conflict of interest.

\section{Acknowledgements}

This work was supported by institutional research funding (IUT2032) from the Estonian Ministry of Education and Research; the European Union through the European Regional Development Fund (Centre of Excellence FIBIR); the Estonian Doctoral School of Ecology and Environmental Sciences.

\section{References}

Alvarez Rojas, C.A., Romig, T., Lightowlers, M.W., 2014. Echinococcus granulosus sensu lato genotypes infecting humans - review of current knowledge. Int. J. Parasitol. 44:9-18. http://dx.doi.org/10.1016/j.ijpara.2013.08.008.

Andresiuk, M.V., Gordo, F.P., Saarma, M., Elissondo, M.C., Taraborelli, A., Casalongue, C., Denegri, G., Saarma, U., 2013. Echinococcus granulosus genotype G1 dominated in cattle and sheep during 2003-2006 in Buenos Aires province, an endemic area for cystic echinococcosis in Argentina. Acta Trop. 127:136-142. http://dx.doi.org/10.1016/j. actatropica.2013.04.008

Bandelt, H.J., Forster, P., Rohl, A., 1999. Median-joining networks for inferring intraspecific phylogenies. Mol. Biol. Evol. 16, 37-48.

Boufana, B., Lett, W.S., Lahmar, S., Buishi, I., Bodell, A.J., Varcasia, A., Casulli, A., Beeching, N.J., Campbell, F., Terlizzo, M., McManus, D.P., Craig, P.S., 2015. Echinococcus equinus and Echinococcus granulosus sensu stricto from the United Kingdom: genetic diversity and haplotypic variation. Int. J. Parasitol. 45, 161-166.
Bowles, J., Blair, D., McManus, D., 1992. Genetic variants within the genus Echinococcus identified by mitochondrial-DNA sequencing. Mol. Biochem. Parasitol. 54:165-174. http://dx.doi.org/10.1016/0166-6851(92)90109-W.

Bowles, J., Blair, D., McManus, D.P., 1994. Molecular genetic characterization of the cervid strain ('northern form') of Echinococcus granulosus. Parasitology 109:215-221. http:// dx.doi.org/10.1017/S0031182000076332.

Busi, M., Snabel, V., Varcasia, A., Garippa, G., Perrone, V., De Liberato, C., D'Amelio, S., 2007. Genetic variation within and between G1 and G3 genotypes of Echinococcus granulosus in Italy revealed by multilocus DNA sequencing. Vet. Parasitol. 150: 75-83. http://dx.doi.org/10.1016/j.vetpar.2007.09.003.

Casulli, A., Interisano, M., Sreter, T., Chitimia, L., Kirkova, Z., La Rosa, G., Pozio, E., 2012. Genetic variability of Echinococcus granulosus sensu stricto in Europe inferred by mitochondrial DNA sequences. Infect. Genet. Evol. 12:377-383. http://dx.doi.org/10. 1016/j.meegid.2011.12.014.

Cucher, M.A., Macchiaroli, N., Baldi, G., Camicia, F., Prada, L, Maldonado, L, Avila, H.G., Fox, A., Gutiérrez, A., Negro, P., Lopez, R., Jensen, O., Rosenzvit, M., Kamenetzky, L., 2016. Cystic echinococcosis in South America: systematic review of species and genotypes of Echinococcus granulosus sensu lato in humans and natural domestic hosts. Tropical Med. Int. Health 21:166-175. http://dx.doi.org/10.1111/tmi.12647.

Dakkak, A., 2010. Echinococcosis/hydatidosis: a severe threat in Mediterranean countries. Vet. Parasitol. 174:2-11. http://dx.doi.org/10.1016/j.vetpar.2010.08.009.

Daumerie, D., Savioli, L. Crompton, D.W.T, Peters, P., 2010. Working to Overcome the Global Impact of Neglected Tropical Diseases: First WHO Report on Neglected Tropical Diseases. World Health Organization, France.

Deplazes, P., van Knapen, F., Schweiger, A., Overgaauw, P.A., 2011. Role of pet dogs and cats in the transmission of helminthic zoonoses in Europe, with a focus on echinococcosis and toxocarosis. Vet. Parasitol. 182:41-53. http://dx.doi.org/10.1016/j.vetpar. 2011.07.014.

Eckert, J., Gemmell, M.A., Meslin, F.-X., Pawlowski, Z.S., 2001. WHO/OIE Manual on Echinococcosis in Humans and Animals: A Public Health Problem of Global Concern. WHO/OIE, Paris:pp. 72-99. http://apps.who.int/iris/bitstream/10665/42427/1/ 929044522X.pdf.

FAO/WHO [Food and Agriculture Organization of the United Nations/World Health Organization], 2014. Multicriteria-based ranking for Risk Management of Foodborne Parasites. Microbiological Risk Assessment Series No. 23 (Rome. 302 pp.).

Gholami, S., Irshadullah, M., Mobedi, I., 2011. Rostellar hook morphology of larval Echinococcus granulosus isolates from the Indian buffalo and Iranian sheep, cattle and camel. J. Helminthol. 85:239-245. http://dx.doi.org/10.1017/S0022149X10000520.

Hajialilo, M., Fasihi Harandi, M., Sharbatkhori, M., Mirhendi, H., Rostami, S., 2012. Genetic characterization of Echinococcus granulosus in camels, cattle and sheep from the south-east of Iran indicates the presence of the G3 genotype. J. Helminthol. 86: 263-270. http://dx.doi.org/10.1017/S0022149X11000320.

Hüttner, M., Nakao, M., Wassermann, T., Siefert, L., Boomker, J.D.F., Dinkel, A., Sako, Y., Mackenstedt, U., Romig, T., Ito, A., 2008. Genetic characterization and phylogenetic position of Echinococcus felidis Ortlepp, 1937 (Cestoda: Taeniidae) from the African lion. Int. J. Parasitol. 38:861-868. http://dx.doi.org/10.1016/j.ijpara.2007.10.013.

Keis, M., Remm, J., Ho, S.Y.W., Davison, J., Tammeleht, E., Tumanov, I.L., Saveljev, A.P. Männil, P., Kojola, I., Abramov, A.V., Margus, T., Saarma, U., 2013. Complete mitochondrial genomes and a novel spatial genetic method reveal cryptic phylogeographic structure and migration patterns among brown bears in north-western Eurasia. J. Biogeogr. 40:915-927. http://dx.doi.org/10.1111/jbi.12043.

Kinkar, L., Laurimäe, T., Simsek, S., Balkaya, I., Casulli, A., Manfredi, M.T., Ponce-Gordo, F., Varcasia, A., Lavikainen, A., Gonzalez, L.M., Rehbein, S., van der Giessen, J., Sprong, H., Saarma, U., 2016. High-resolution phylogeography of zoonotic tapeworm Echinococcus granulosus sensu stricto genotype G1 with an emphasis on its distribution in Turkey, Italy and Spain. Parasitology 143:1790-1801. http://dx.doi.org/10.1017/ S0031182016001530

Knapp, J., Gottstein, B., Saarma, U., Millon, L., 2015. Taxonomy, phylogeny and molecular epidemiology of Echinococcus multilocularis: from fundamental knowledge to health ecology. Vet. Parasitol. 213:85-91. http://dx.doi.org/10.1016/j.vetpar. 2015.07.030

Knapp, J., Nakao, M., Yanagida, T., Okamoto, M., Saarma, U., Lavikainen, A., Ito, A., 2011. Phylogenetic relationships within Echinococcus and Taenia tapeworms (Cestoda: Taeniidae): an inference from nuclear protein-coding genes. Mol. Phylogenet. Evol. 61:628-638. http://dx.doi.org/10.1016/j.ympev.2011.07.022.

Lavikainen, A., Lehtinen, M., Meri, T., Hirvelä-Koski, V., Meri, S., 2003. Molecular genetic characterization of the Fennoscandian cervid strain, a new genotypic group (G10) of Echinococcus granulosus. Parasitology 127, 207-215.

Laurimaa, L., Davison, J., Süld, K., Plumer, L., Oja, R., Moks, E., Keis, M., Hindrikson, M., Kinkar, L., Laurimäe, T., Abner, J., Remm, J., Anijalg, P., Saarma, U., 2015a. First report of highly pathogenic Echinococcus granulosus genotype G1 in dogs in European urban environment. Parasit. Vectors 8:182. http://dx.doi.org/10.1186/s13071-015-0796-3.

Laurimaa, L., Davison, J., Plumer, L., Süld, K., Oja, R., Moks, E., Keis, M., Hindrikson, M., Kinkar, L., Laurimäe, T., Abner, J., Remm, J., Anijalg, P., Saarma, U., 2015b. Non-invasive molecular diagnostics identifies Echinococcus multilocularis spillover to an urban area in Estonia. Emerg. Infect. Dis. 21:163-164. http://dx.doi.org/10.3201/eid2101. 140136.

Laurimäe, T., Kinkar, L., Andresiuk, V., Haag, K.L., Ponce-Gordo, F., Acosta-Jamett, G., Garate, T., Gonzalez, L.M., Saarma, U., 2016. Genetic diversity and phylogeography of highly zoonotic Echinococcus granulosus genotype G1 in the Americas (Argentina, Brazil, Chile and Mexico) based on 8279 bp of mtDNA. Infect. Genet. Evol. 45: 290-296. http://dx.doi.org/10.1016/j.meegid.2016.09.015.

Le, T.H., Pearson, M.S., Blair, D., Dai, N., Zhang, L.H., McManus, D.P., 2002. Complete mitochondrial genomes confirm the distinctiveness of the horse-dog and sheep-dog strains of Echinococcus granulosus. Parasitology 124:97-112. http://dx.doi.org/10. 1017/S0031182001008976. 
Lymbery, A.J., 2016. Phylogenetic pattern, evolutionary processes and species delimitation in the genus Echinococcus. Adv. Parasitol. http://dx.doi.org/10.1016/bs.apar.2016.07.002.

Marcinkute, A., Šarkunas, M., Moks, E., Saarma, U., Jokelainen, P., Bagrade, G., Laivacuma, S., Strupas, K., Sokolovas, V., Deplazes, P., 2015. Echinococcus infections in the Baltic region. Vet. Parasitol. 213:121-131. http://dx.doi.org/10.1016/j.vetpar.2015.07.032.

Moks, E., Jõgisalu, I., Saarma, U., Talvik, H., Järvis, T., Valdmann, H., 2006. Helminthologic survey of the wolf (Canis lupus) in Estonia, with an emphasis on Echinococcus granulosus. J. Wildl. Dis. 42, 359-365.

Moks, E., Jõgisalu, I., Valdmann, H., Saarma, U., 2008. First report of Echinococcus granulosus G8 in Eurasia and a reappraisal of the phylogenetic relationships of 'genotypes' G5-G10. Parasitology 135:647-654. http://dx.doi.org/10.1017/ S0031182008004198.

Nakao, M., Lavikainen, A., Hoberg, E., 2015. Is Echinococcus intermedius a valid species? Trends Parasitol. 31:342-343. http://dx.doi.org/10.1016/j.pt.2015.04.012.

Nakao, M., McManus, D.P., Schantz, P.M., Craig, P.S., Ito, A., 2007. A molecular phylogeny of the genus Echinococcus inferred from complete mitochondrial genomes. Parasitology 134:713-722. http://dx.doi.org/10.1017/S0031182006001934.

Nakao, M., Yanagida, T., Konyaev, S., Lavikainen, A., Odnokurtsev, V.A., Zaikov, V.A., Ito, A 2013. Mitochondrial phylogeny of the genus Echinococcus (Cestoda: Taeniidae) with emphasis on relationships among Echinococcus canadensis genotypes. Parasitology 140:1625-1636. http://dx.doi.org/10.1017/S0031182013000565.

Possenti, A., Manzano-Román, R., Sánchez-Ovejero, C., Boufana, B., La Torre, G., SilesLucas, M., Casulli, A., 2016. Potential risk factors associated with human cystic echinococcosis: systematic review and meta-analysis. PLoS Negl. Trop. Dis. 10, e0005114. http://dx.doi.org/10.1371/journal.pntd.0005114.

Romig, T., Ebi, D., Wassermann, M., 2015. Taxonomy and molecular epidemiology of Echinococcus granulosus sensu lato. Vet. Parasitol. 213:76-84. http://dx.doi.org/10.1016/ j.vetpar.2015.07.035.

Rostami, S., Shariat Torbaghan, S., Dabiri, S., Babaei, Z., Mohammadi, M.A., Sharbatkhori, M., Fasihi Harandi, M., 2015. Genetic characterization of Echinococcus granulosus from a large number of formalin-fixed, paraffin-embedded tissue. Am.J.Trop. Med. Hyg. 92:588-594. http://dx.doi.org/10.4269/ajtmh.14-0585.

Saarma, U., Jogisalu, I., Moks, E., Varcasia, A., Lavikainen, A., Oksanen, A., Simsek, S. Andresiuk, V., Denegri, G., Gonzalez, L.M., Ferrer, E., Garate, T., Rinaldi, L., Maravilla,
P., 2009. A novel phylogeny for the genus Echinococcus, based on nuclear data, challenges relationships based on mitochondrial evidence. Parasitology 136:317-328. http://dx.doi.org/10.1017/S0031182008005453.

Thompson, R.C.A., 2008. The taxonomy, phylogeny and transmission of Echinococcus. Exp. Parasitol. 119:439-446. http://dx.doi.org/10.1016/j.exppara.2008.04.016.

Thompson, R.C.A., 2016. Biology and Systematics of Echinococcus. Adv. Parasitol. http://dx. doi.org/10.1016/bs.apar.2016.07.001.

Thompson, R.C., Lymbery, A.J., Constantine, C.C., 1995. Variation in Echinococcus: towards a taxonomic revision of the genus. Adv. Parasitol. 35, 145-176.

Thompson, R.C.A., McManus, D.P., 2002. Towards a taxonomic revision of the genus Echinococcus. Trends Parasitol. 18:452-457. http://dx.doi.org/10.1016/S14714922(02)02358-9.

Vural, G., Baca, A.U., Gauci, C.G., Bagci, O., Gicik, Y., Lightowlers, M.W., 2008. Variability in the Echinococcus granulosus cytochrome c oxidase 1 mitochondrial gene sequence from livestock in Turkey and a re-appraisal of the G1-3 genotype cluster. Vet. Parasitol. 154:347-350. http://dx.doi.org/10.1016/j.vetpar.2008.03.020.

Wang, N., Xie, Y., Liu, T., Zhong, X., Wang, J., Hu, D., Wang, S., Gu, X., Peng, X., Yang, G. 2016. The complete mitochondrial genome of G3 genotype of Echinococcus granulosus (Cestoda: Taeniidae). Mitochondrial DNA 27:1701-1702. http://dx.doi. org/10.3109/19401736.2014.961129.

Wassermann, M., Woldeyes, D., Gerbi, B.M., Ebi, D., Zeyhle, E., Mackenstedt, U., Petros, B. Tilahun, G., Kern, P., Romig, T., 2016. A novel zoonotic genotype related to Echinococcus granulosus sensu stricto from southern Ethiopia. Int. J. Parasitol. 46:663-668. http://dx.doi.org/10.1016/j.ijpara.2016.04.005.

Yanagida, T., Mohammadzadeh, T., Kamhawi, S., Nakao, M., Sadjjadi, S.M., Hijjawi, N., Abdel-Hafez, S.K., Sako, Y., Okamoto, M., Ito, A., 2012. Genetic polymorphisms of Echinococcus granulosus sensu stricto in the Middle East. Parasitol. Int. 61:599-603. http://dx.doi.org/10.1016/j.parint.2012.05.014.

Zhang, W., Zhang, Z., Wu, W., Shi, B., Li, J., Zhou, X., Wen, H., McManus, D.P., 2015. Epidemiology and control of echinococcosis in central Asia, with particular reference to the People's Republic of China. Acta Trop. 141:235-243. http://dx.doi.org/10.1016/j actatropica.2014.03.014. 